(C) 2021 Universidad Nacional Autónoma de México, Facultad de Estudios Superiores Zaragoza.

Este es un artículo Open Access bajo la licencia CC BY-NC-ND (http://creativecommons.org/licenses/by-nc-nd/4.0/).

TIP Revista Especializada en Ciencias Químico-Biológicas, 24: 1-15, 2021.

https://doi.org/10.22201/fesz.23958723e.2021.326

\title{
Fitorremediación: Alternativa biotecnológica para recuperar suelos contaminados con DDT. Una revisión
}

\author{
Caliope Mendarte-Alquisira, Alejandro Alarcón \\ y Ronald Ferrera-Cerrato* \\ Área de Microbiología, Postgrado de Edafología, Colegio de \\ Postgraduados, Carretera Federal México-Texcoco km 36.5, Montecillo \\ 56230, Estado de México, México. E-mail: rferreracerrato@gmail.com
}

\begin{abstract}
RESUMEN
El DDT (Dicloro Difenil Tricloroetano o 1,1,1-tricloro-2,2-bis-etano) representa un riesgo importante para la salud humana, debido a que se asocia con enfermedades como cáncer de mama, Alzheimer, Parkinson y su acumulación en sangre. Los recientes hallazgos del uso clandestino del DDT como agroquímico hacen necesaria la implementación de tecnologías de recuperación de suelos agrícolas contaminados con este compuesto. La fitorremediación es una tecnología sustentable, que utiliza el potencial de las plantas para remover contaminantes orgánicos e inorgánicos. Esta tecnología es mejorada con la inoculación de microorganismos rizosféricos que median el transporte de nutrientes y degradan compuestos orgánicos como el DDT. Esta revisión recopila información científica de los últimos diez años sobre: fitorremediación y fitorremediación asistida por microorganismos en sitios contaminados por DDT, y sus metabolitos diclorodifenildicloroetileno (DDE) y diclorodifenildicloroetano (DDD. Además, se resaltan los puntos más importantes que hacen de la fitorremediación una estrategia para la recuperación de suelos contaminados con DDT, DDE y DDD.

Palabras clave: recuperación de suelos agrícolas, agua contaminada, plaguicidas organoclorados, plantas, microorganismos.
\end{abstract}

Phytoremediation: Biotechnological alternative for recovering DDT-contaminated soils. A review

\begin{abstract}
DDT (dichloride diphenyl trichloroethane or 1,1,1-trichloro-2,2-bis-ethane) represent a significant risk for human health. This is since it is associated with diseases such as breast cancer, Alzheimer's, Parkinson's, and its accumulation in the blood. The recent findings of the clandestine use of DDT agrochemical make it necessary to implement technologies for the recovery of agricultural soils contaminated with this compound. Phytoremediation is a sustainable technology that uses the potential of plants to remove organic and inorganic contaminants. This technology is improved with the inoculation of rhizospheric microorganisms that mediate the transport of nutrients and even degrade organic compounds such as DDT. This review compiles scientific information related to the study of phytoremediation and microorganism-assisted phytoremediation of sites contaminated by DDT and its metabolites, dichlorodiphenyldichlorethylene (DDE) and dichlorodiphenyldichloroethane (DDD), in the last 10 years. In addition, the most important points that make phytoremediation a strategy for the recovery of soils contaminated with DDT, DDE and DDD are highlighted. Keywords: agricultural soil recovery, contaminated water, organochlorine pesticides, plants, microorganisms.
\end{abstract}




\section{INTRODUCCIÓN}

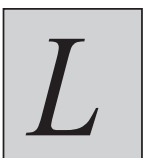

os plaguicidas organoclorados (OCP, por sus siglas en inglés) se han utilizado para evitar la pérdida de los cultivos agrícolas y controlar vectores transmisores de malaria, paludismo y dengue, entre otras (Leal et al., 2014; Xia, Ma, Liu \& Fan, 2012; Hancock et al., 2018). Los OCP tienen gran persistencia en el ambiente y gran afinidad por los tejidos lipídicos, por lo que pueden bioacumularse a través de la cadena alimentaria, estas características hacen que los OCP se consideren contaminantes orgánicos persistentes (POP, por sus siglas en inglés). Dentro de los POP se encuentra el DDT (Dicloro Difenil Tricloroetano o 1,1,1-tricloro-2,2-bis-etano), compuesto considerado uno de los más tóxicos y recalcitrantes, por esa razón fue prohibido desde 1970, sin embargo, los estudios demuestran que se ha seguido utilizando de manera clandestina en la agricultura (Velasco, Hernández, Ramírez \& Ortíz, 2014; Ponce-Vélez \& Botello, 2018; Giácoman-Vallejos, Lizarraga-Castro, Ponce-Caballero, González-Sánchez \& Hernández-Núñez, 2018). Una forma de recuperar suelos contaminados con compuestos orgánicos e inorgánicos, incluyendo los OCP, considera alternativas ecológicas y sustentables como la fitorremediación. La fitorremediación utiliza plantas y microorganismos asociados para filtrar, remover, degradar, volatilizar y estabilizar contaminantes (Pilon-Smits, 2005). Por lo anterior, el presente documento analiza la información científica de los estudios realizados en los últimos diez años sobre: la fitorremediación y fitorremediación asistida por microorganismos de sitios contaminados con DDT y sus metabolitos, el diclorodifenildicloroetileno (DDE) y el diclorodifenildicloroetano (DDD). Además, se resaltan los puntos más importantes que hacen de la fitorremediación una estrategia para limpiar suelos contaminados con DDT, DDE y DDD.

\section{Plaguicidas organoclorados}

La necesidad por incrementar la producción de alimentos de origen agrícola ha requerido de la utilización de compuestos químicos para el control de diversas plagas, donde los OCP han representado una opción para cubrir esta necesidad. Los OCP son muy estables y pueden tardar días, meses o años en transformarse en moléculas menos dañinas; pueden ser sometidos a evaporación después de su aplicación, y ser dispersados a regiones donde no se han utilizado; por estas características los OCP son considerados POP. La manipulación inadecuada de los POP ha ocasionado severos daños ambientales y riesgos a la salud humana (Nurzhanova, Kalugin \& Zhambakin, 2013; Younas, Hilber, Rehman, Khwaja \& Bucheli, 2013).

De acuerdo con la Organización Mundial de la Salud (OMS) (WHO, por sus siglas en inglés), plaguicidas como los OCP, son causantes de muerte por suicidio, sobre todo en lugares de ingresos económicos intermedios y bajos (OMS, 2019). Se calcula que el suicidio por causa de la ingestión de plaguicidas asciende a 186,000 muertes (OMS, 2019). Además, múltiples estudios demuestran que los OCP causan intoxicaciones graves y están relacionados con alteraciones neurológicas, reproductivas, cáncer y defectos congénitos (Bornman, Jager, Worku, Farias \& Reif, 2010; Genthe et al., 2013; Wu, Cohn, Cirillo, Santella \& Terry, 2019). Este problema se acentúa, ya que algunos OCP prohibidos se siguen utilizando en diversos países y se dispersan por agua, suelo y aire.

Acorde con el Convenio de Estocolmo, los POP se dividen en tres categorías: i) plaguicidas como aldrina, clordano, dicloro difenil tricloroetano (DDT), dieldrina, endrina, heptaclor, hexaclorobenceno, mixer, toxafeno; ii) químicos industriales, que incluyen hexaclorobenceno, bifenilos policlorados (PCBs); y iii) los sub-productos hexaclorobenceno, dibenzo-p-dioxinas policloradas, dibenzofuranos policlorados y derivados de PCBs. A partir de la cuarta reunión del Convenio de Estocolmo (2009), se han incluido 16 sustancias entre los POP y son: alfa-hexaclorociclohexano, betahexaclorociclohexano, clordecano, hexabromobifenilo, hexabromociclododecano, hexabromodifenil éter y heptabromodifenil éter, también hexaclorobutadieno, lindano, pentaclorobenzeno, pentaclorofenol con sus sales y éteres, ácido perfluorooctano sulfónico, sus sales y fluoruro perfluorooctano sulfonilo, naftalenos policlorados, endosulfán y sus isómeros, éter tetrabromodifenilo, éter pentabromodifenilo, éter decabromodifenilo, y parafinas de cadena corta cloradas (UNEP, 2001)

A pesar de ser varios los compuestos considerados como POP, el DDT ha sido de los más importantes por sus propiedades e intensa utilización durante épocas de guerra y ahora en el control de vectores transmisores de enfermedades, además de su uso clandestino en la agricultura.

\section{El Caso particular del dicloro difenil TRICLOROETANO (DDT)}

El DDT (Dicloro Difenil Tricloroetano o 1,1,1-tricloro-2,2-bisetano) es un plaguicida organoclorado sintetizado por primera vez en 1874 por el químico austriaco Othmar Zeidler, años más tarde, en 1939, el científico suizo Paul Hermann Müller descubrió las propiedades del DDT como plaguicida y fue así como comenzó a ser utilizado en el control de plagas agrícolas y vectores de malaria, tifus, fiebre amarilla y dengue (Gamboa, 2014). Las propiedades fisicoquímicas del DDT lo hacen un contaminante de gran persistencia en el ambiente (Tabla I) (Xia et al., 2012). El DDT es incorporado al agua superficial reciclada de actividades agrícolas, y llega a acumularse incluso en organismos de sitios donde nunca se ha utilizado (Fiedler, 2007). El uso del DDT se prohibió en 1970 debido al impacto negativo en la vida silvestre y a los efectos tóxicos en la salud humana (Kucher, Ricking \& Schwarzbauer, 2019).

En la obra "La Primavera Silenciosa" publicada por la bióloga marina Rachel Carson en 1962, se resalta que el DDT no sólo 
Tabla I. Propiedades fisicoquímicas del DDT.

\begin{tabular}{|c|c|}
\hline Propiedad fisicoquímica & $p^{\prime} p^{\prime}-\mathrm{DDT}$ \\
\hline apeso molecular & $354.5 \mathrm{~g} / \mathrm{mol}$ \\
\hline${ }^{\mathrm{a} D e n s i d a d}\left(20^{\circ} \mathrm{C}\right)$ & $1.016 \mathrm{~kg} / \mathrm{L}$ \\
\hline${ }^{\mathrm{a} E s t a d o}$ físico & Sólido (cristales) \\
\hline${ }^{\mathrm{a} C}$ Color & Blanco \\
\hline${ }^{\text {aPunto de ebullición }}$ & $180^{\circ} \mathrm{C}$ \\
\hline aPunto de fusión & $108.5^{\circ} \mathrm{C}$ \\
\hline${ }^{\text {aPunto de inflamabilidad }}$ & $72.2^{\circ} \mathrm{C}$ \\
\hline${ }^{\text {aS Solubilidad en agua }}$ & Parcialmente insoluble \\
\hline $\begin{array}{l}\text { aSolubilidad en compuestos } \\
\text { orgánicos }\end{array}$ & $\begin{array}{l}\text { Alta; } 2 \mathrm{~g} / 100 \mathrm{~mL} \text { etanol; } \\
28 \mathrm{~g} / 100 \mathrm{~mL} \text { éter. }\end{array}$ \\
\hline${ }^{\mathrm{b}} \log \mathrm{K}_{o w}$ & 6.91 \\
\hline${ }^{\mathrm{b}} \log \mathrm{K}_{o c}$ & 6.59 \\
\hline${ }^{\mathrm{a} G r a v e d a d ~ e s p e c i ́ f i c a ~}$ & 1.55 \\
\hline 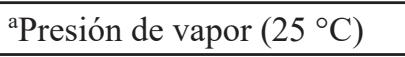 & $2.53 / 10^{-5} \mathrm{~Pa}$ \\
\hline${ }^{\mathrm{b}}$ Constante de Henry & $2 / 10^{-6}\left(\mathrm{~mol} / \mathrm{L}^{*} \mathrm{~atm}\right)$ \\
\hline aVida media en suelos & $170,000 \mathrm{~h}$ \\
\hline${ }^{\text {aVida media en agua }}$ & $1,984 \mathrm{~h}$ \\
\hline${ }^{\mathrm{a}}$ Vida media en aire & $170 \mathrm{~h}$ \\
\hline 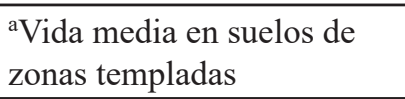 & $55,000 \mathrm{~h}$ \\
\hline 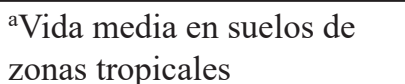 & $17,000 \mathrm{~h}$ \\
\hline
\end{tabular}

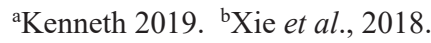

acaba con las plagas objetivo, sino que también afecta a otros organismos, queda libre en el ecosistema, se bioacumula y se biomagnifica (Gamboa, 2014). La toxicidad del DDT se ha asociado con malformaciones congénitas, abortos, y enfermedades como cáncer de mama (Bornman et al., 2010; Genthe et al., 2013; Wu et al., 2019; Cohn, Cirillo \& Terry, 2019), Alzheimer y Parkinson (Richardson et al., 2014) y disminución de la progesterona en humanos (Munier et al.,2021). Lo anterior debido a que el DDT es un disruptor endócrino, además de causar la despolarización de las membranas celulares y la inducción de enzimas hepáticas con actividad de oxidasas y de transferasas también disminuye el AMP cíclico (Fernícola 1985; Bornman et al., 2010; Munier et al., 2021).

Por sus propiedades fisicoquímicas (Tabla I), el DDT puede ser acumulado y biodegradado en condiciones aerobias y anaerobias. La biodegradación del DDT se lleva a cabo por una serie de enzimas con actividad de oxidasas y monooxigenasas, mientras que en la acumulación participan enzimas con actividad de transferasas y antioxidantes no enzimáticos como el glutatión. Durante la biodegradación del DDT se producen diferentes metabolitos, dependiendo de la ruta de degradación, así en la biodegradación aerobia del DDT hay deshidrocloración y el metabolito que se obtiene es el diclorodifenildicloroetileno (DDE), mientras que en la biodegradación anaerobia hay una descloración reductiva y se obtiene el diclorodifenildicloroetano (DDD) (Figura 1). Muchas de las enzimas de detoxificación y metabolismo de plaguicidas son similares en plantas y microorganismos (Van Eerd, Hoagland \& Hall, 2003; Tarla et al., 2020). Se conoce que las plantas tienen la capacidad de acumular y degradar DDT. Estudios realizados con DDT marcado radiactivamente $\left({ }^{14} \mathrm{C}\right.$ DDT) demuestran que durante el metabolismo del ${ }^{14} \mathrm{C}$ DDT en las plantas se producen los metabolitos DDE y DDD además de acumularse (Menn, Still \& Ruhr, 1977; Suresh, Sherkhane, Kale, Eapen \& Ravishankar, 2005). Estos procesos de degradación dependen del tipo de planta, condiciones ambientales y tiempo de contacto entre los contaminantes y los organismos.

Por su alta persistencia, eficacia y a pesar de los riesgos, el DDT se autorizó en 2006 para controlar vectores de malaria en diferentes sitios, acorde con los lineamientos de la Organización Mundial de la Salud (WHO, 2011). Estudios dirigidos por la Organización Panamericana de Salud demuestran que, en las comunidades de Guatemala, El Salvador, Honduras, Costa Rica, Panamá y México, el rociado de DDT en el interior de los hogares provoca acumulación del compuesto en el suelo interior y exterior de las casas (Pérez-Maldonado et al., 2010). En México, en los estados de Oaxaca (Yáñez, OrtizPérez, Batres, Borja-Aburto \& Díaz-Barriga, 2002), Chiapas (Martínez-Salinas, Díaz-Barriga, Batres-Esquivel \& PérezMaldonado, 2011), Chihuahua (Díaz-Barriga et al., 2012), Sinaloa (García-de la Parra et al., 2012), Tabasco (Torres-Dosal et al., 2012), San Luis Potosí (Velasco et al., 2014) y Yucatán (Giácoman-Vallejos et al., 2018) el DDT se ha encontrado en concentraciones que exceden los límites permisibles en suelos, sedimentos, mantos acuíferos, organismos marinos e incluso mujeres y niños de diversas edades (hasta $26,980 \mu \mathrm{g} / \mathrm{kg}$ de DDT en suelo agrícola y 58,270 $\mu \mathrm{g}$ de DDT/L de suero humano). Además, existen indicadores del uso ilegal del DDT como agroquímico en África, China y México (Gyalpo et al., 2012; Mochungong \& Zhu, 2015; Mahugija, Nambela \& Mmochi, 2017; Ponce-Vélez \& Botello, 2018; Giácoman-Vallejos et al., 2018; Peng et al., 2020; Sun et al., 2020); en Europa el DDT, DDE y DDD, son de los insecticidas de mayor presencia en los suelos agrícolas (Silva et al., 2019), a pesar de haberse dejado de utilizar desde hace varias décadas. Esta situación ocurre también en países de América del Sur como Argentina (Mitton, Miglioranza, Gonzalez, Shimabukuro \& Monserrat, 2014) y en el continente africano (Odewale, Sosan, Oyekunle \& Adeleye, 2021; Woldetsadik et al., 2021).

Las propiedades fisicoquímicas del DDT (Tabla I) le permiten ser monitoreado en poblaciones humanas a través del análisis de leche materna, sangre y del tejido adiposo, donde la existencia de DDT en estos componentes indica exposición reciente 


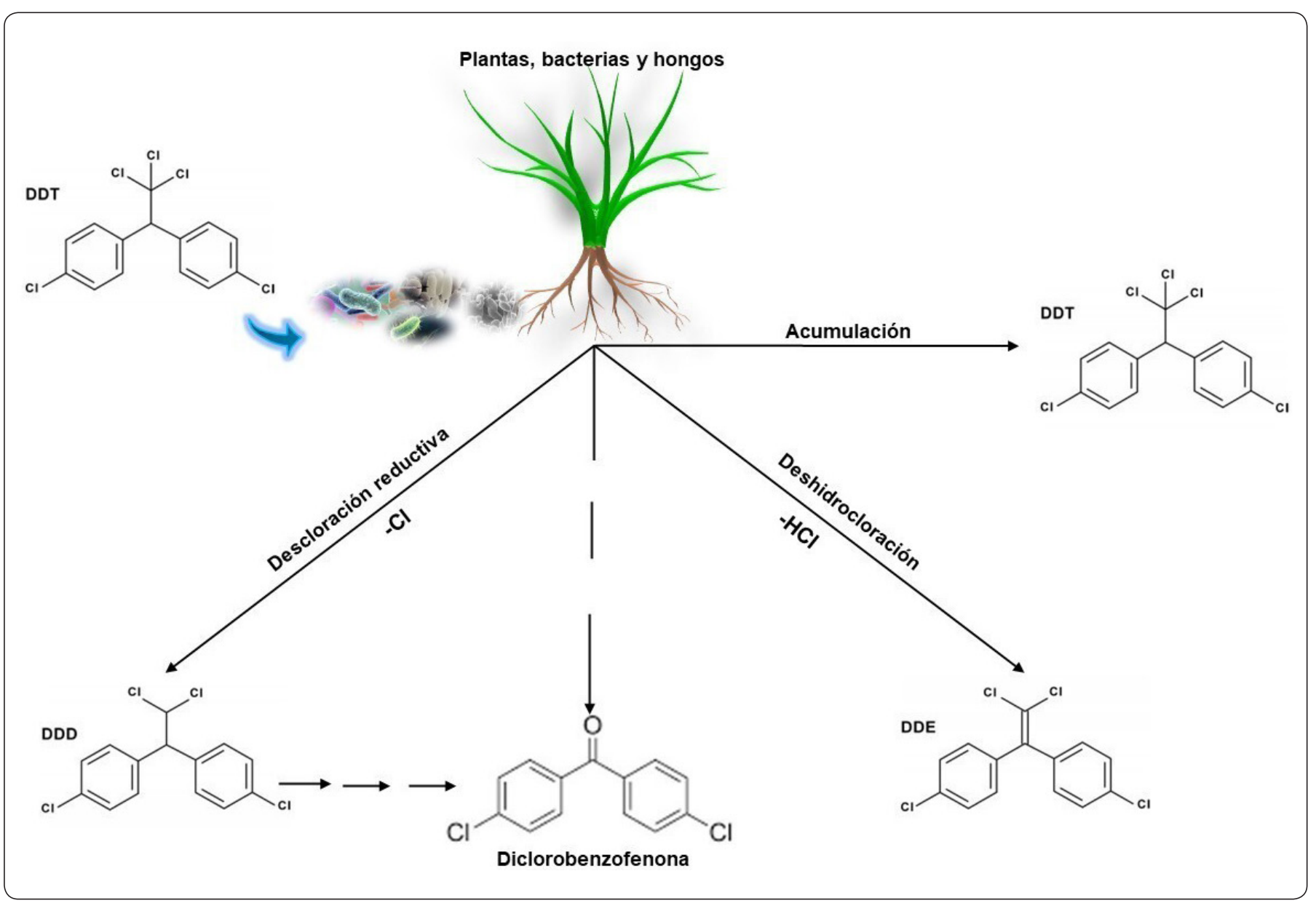

Figura 1. Biotransformación y acumulación del DDT por plantas, bacterias y hongos, modificado de Menn et al. (1977).

al compuesto (Arrebola, Fernández, Olea, Ramo \& MartinOlmedo, 2013; Chávez-Almazán et al., 2018; Cupul-Uicab et al., 2020), además, se ha observado que el DDT puede ser transferido de madres a hijos durante el embarazo a través de la placenta y el cordón umbilical, sin que exista una correlación en el contenido entre lo encontrado en la madre y el feto (Vizcaino, Grimalt, Fernández-Somoano \& Tardon, 2014).

\section{LA FITORREMEDIACIÓN Y SUS TECNOLOGÍAS}

Como parte de los esfuerzos para recuperar suelos contaminados con compuestos inorgánicos y orgánicos, incluyendo los plaguicidas organoclorados, se han estudiado alternativas rentables, no invasivas, ecológicas y sustentables como la fitorremediación. Además, contribuye a evitar la erosión, modifica la composición física, química, biológica y nutrimental y con ello mejorar la productividad y optimización del suelo. La fitorremediación es el uso de plantas y los microorganismos asociados para filtrar, remover, degradar, volatilizar y estabilizar los contaminantes (Pilon-Smits, 2005). De acuerdo con Cunningham, Berti \& Huang (1995), la fitorremediación representa una alternativa efectiva y de bajo costo para la remediación de los sistemas contaminados. Mientras que los costos de la remediación físico-química se encuentran entre los U\$200-10,000 hectárea ${ }^{-1}$, el uso de la fitorremediación tiene un costo de U\$0.02-1.00 $\mathrm{m}^{3}$ por año, lo que representa varios órdenes de magnitud menos que los costos asociados con tecnologías de remediación físico-química (Cunningham et al., 1995). Por su parte, Farraji, Zaman, Tajuddin \& Faraji (2016) reportan que los costos de la fitorremediación además de ser menores que otros tratamientos, requieren de menores gastos extra (Tabla II). Los costos de la fitorremediación pueden variar y están altamente correlacionados con el tipo y concentración del contaminante, y con las propiedades del suelo o cuerpos de agua, condiciones ambientales, e impacto del contaminante en la cadena alimentaria. De cualquier manera, la fitorremediación es el tratamiento con menor costo y alta aceptación social en el mundo (Pilon-Smits, 2005; Farraji et al., 2016).

La fitorremediación involucra diversas tecnologías para la descontaminación según el tipo de contaminante en los sistemas y la capacidad de las plantas utilizadas (Figura 2). La rizofiltración se basa en la filtración de los compuestos en cultivos 
Tabla II. Costo de los tratamientos al suelo y requerimientos del suelo al final del tratamiento.

\begin{tabular}{|l|c|l|l|}
\hline \multicolumn{1}{|c|}{ Tratamientos* } & Costos estimados (\$/ton)* & \multicolumn{1}{|c|}{ Gastos extra* } & \multicolumn{1}{c|}{$\begin{array}{c}\text { Estado del suelo después del } \\
\text { tratamiento** }\end{array}$} \\
\hline Fitorremediación & $5-40$ & Monitoreo & No se requiere regeneración \\
\hline Electrocinéticas & $20-200$ & Monitoreo & Requiere regeneración parcial \\
\hline Tratamientos químicos & $100-500$ & Reciclado de los contaminantes & $\begin{array}{l}\text { Requiere de una profunda fase de } \\
\text { regeneración }\end{array}$ \\
\hline Vertederos & $100-500$ & $\begin{array}{l}\text { Transporte, excavación y } \\
\text { monitoreo }\end{array}$ & $\begin{array}{l}\text { No se pueden utilizar para otros } \\
\text { propósitos }\end{array}$ \\
\hline Vitrificación & $75-425$ & Monitoreo (tiempos extensos) & $\begin{array}{l}\text { No se pueden utilizar para otros } \\
\text { propósitos }\end{array}$ \\
\hline
\end{tabular}

* Farraji et al., 2016. ** De la Rosa-Pérez, Teutli-León \& Ramírez-Islas, 2007.

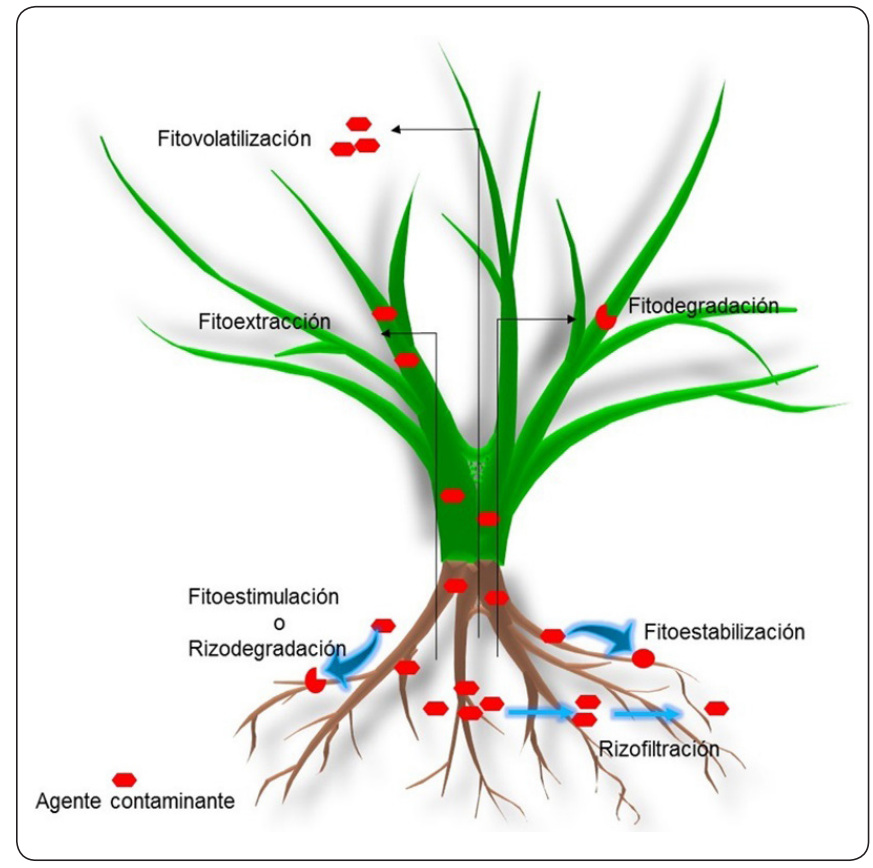

Figura 2. Tecnologías de fitorremediación, modificado de Pilon-Smits (2005).

hidropónicos, en los que las plantas actúan como una barrera que previene la contaminación en diversos cuerpos de agua y la lixiviación de los compuestos (Ignatius, Arunbabu, Neethu \& Ramasamy, 2014). Las plantas también son utilizadas para extraer los contaminantes y acumularlos en los tejidos aéreos (traslocación) que después se cosechan, lo que se denomina como fitoextracción utilizada para extraer metales y metaloides pesados de suelos y cuerpos de agua, así como compuestos orgánicos de alto peso molecular (Robinson, Anderson \& Dickinson, 2015; Sheoran, Sheoran \& Poonia, 2016). La fitoestabilización estabiliza contaminantes, principalmente metales y metaloides pesados del suelo en el área de la rizosfera, lo que puede prevenir su lixiviación o disminuir su biodisponibilidad (Sylvain et al.,
2016; Najeeb, Ahmad, Zia, Malik \& Zhou, 2017). Las plantas pueden degradar compuestos orgánicos utilizando sus propias enzimas, y a este proceso se le conoce como fitodegradación (Al-Baldawi, Abdullah, Anuar, Suja \& Mushrifah, 2015; He et al., 2017; Chlebek \& Hupert-Kocurek, 2019). En los suelos, la biodegradación de los contaminantes orgánicos se facilita por la actividad microbiana que es estimulada por las plantas, y a esta tecnología se le denomina fitoestimulación o rizodegradación (Glick, 2010; Melo et al., 2017). Una vez que los contaminantes son asimilados por las plantas, éstos pueden ser volatilizados, esto se conoce como fitovolatilización (Wang, Feng, Anderson, Xing \& Shang, 2012; Lee, 2013).

Las tecnologías de la fitorremediación se pueden mejorar mediante la inoculación de microorganismos, lo que ha dado auge a la fitorremediación asistida (Figura 3). Estos estudios incluyen microorganismos endófitos, bacterias promotoras del crecimiento vegetal, hongos micorrízicos arbusculares, hongos filamentosos y hongos septados oscuros (Ullah, Heng, Munis, Fahad \& Yang, 2015). Existen diferentes vías para mejorar la fitorremediación, relacionadas con el mejoramiento de la nutrición vegetal, disminución en el estrés oxidativo en las plantas, así como la remoción y degradación de los contaminantes del suelo (Kong \& Glick, 2017). Los microorganismos pueden mejorar la fitorremediación gracias a que cuentan con las herramientas que les permiten solubilizar nutrientes que son aprovechados por las plantas, también cuentan con un sistema enzimático que les ayuda a controlar las especies reactivas de oxígeno que generan estrés en las plantas, además de contar con las enzimas involucradas en la remoción y degradación de los contaminantes. El éxito en la fitorremediación asistida por microorganismos está relacionada con la especie de planta y microorganismos que se utilizan.

La fitorremediación asistida se realiza para mejorar las tecnologías propias de la fitorremediación, que en condiciones de invernadero y estudios in situ podría tener como consecuencia la bioaumentación, debida a los exudados radicales y a los 


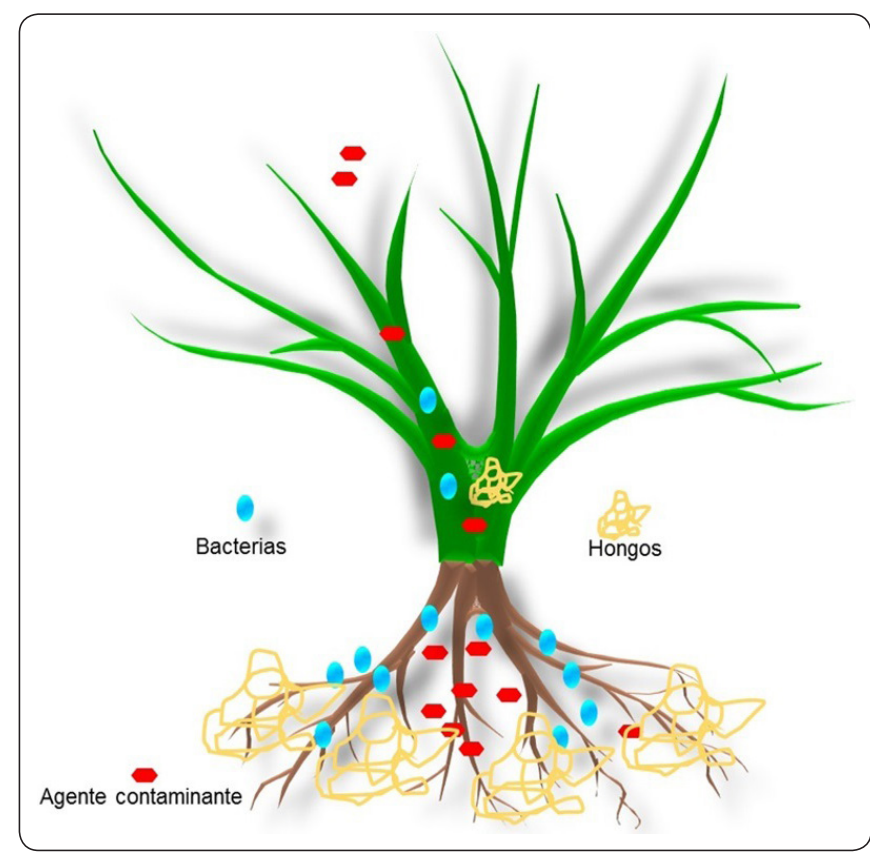

Figura 3. Fitorremediación asistida por microorganismos, modificado de Pilon-Smits (2005).

microorganismos introducidos en el suelo, estos cambios podrían promover el incremento de los microorganismos nativos con capacidades de remover y degradar los contaminantes.

\section{IMPACTO CIENTÍfICO DE LOS ESTUdIOS DE FITORREMEDIACIÓN EN SITIOS CONTAMINADOS CON DDT}

La fitorremediación de suelos contaminados con compuestos orgánicos ha sido en su mayoría ampliamente estudiada, en la remoción de hidrocarburos y con alta efectividad. Los estudios sobre la fitorremediación de suelos contaminados con compuestos organoclorados como el DDT han tenido gran variabilidad en los últimos 10 años, alcanzando hasta seis publicaciones por año en 2018 (Figura 4a). De acuerdo con la Web of Science, los artículos de fitorremediación de suelos contaminados con DDT tienen un promedio de 10.03 citas por artículo, y las citas por año variaron desde $\sim 50$ en 2016 hasta $\sim 60$ citas en 2019 (Figura 4b). Comparado con otros plaguicidas organoclorados, el DDT es el más estudiado en fitorremediación, por ser como ya se mencionó, de los más persistentes y clandestinamente utilizado. Lo anterior hace referencia a un incremento en la relevancia de este tema de investigación con respecto a la problemática ambiental del DDT.

\section{FITORREMEDIACIÓN DE SISTEMAS CONTAMINADOS CON DDT: CASOS DE ESTUDIO}

Los estudios de fitorremediación de suelos, aguas y sedimentos contaminados con DDT realizados en diferentes condiciones como laboratorio, invernadero y estudios in situ contribuyen de manera importante a la recuperación de los suelos agrícolas,

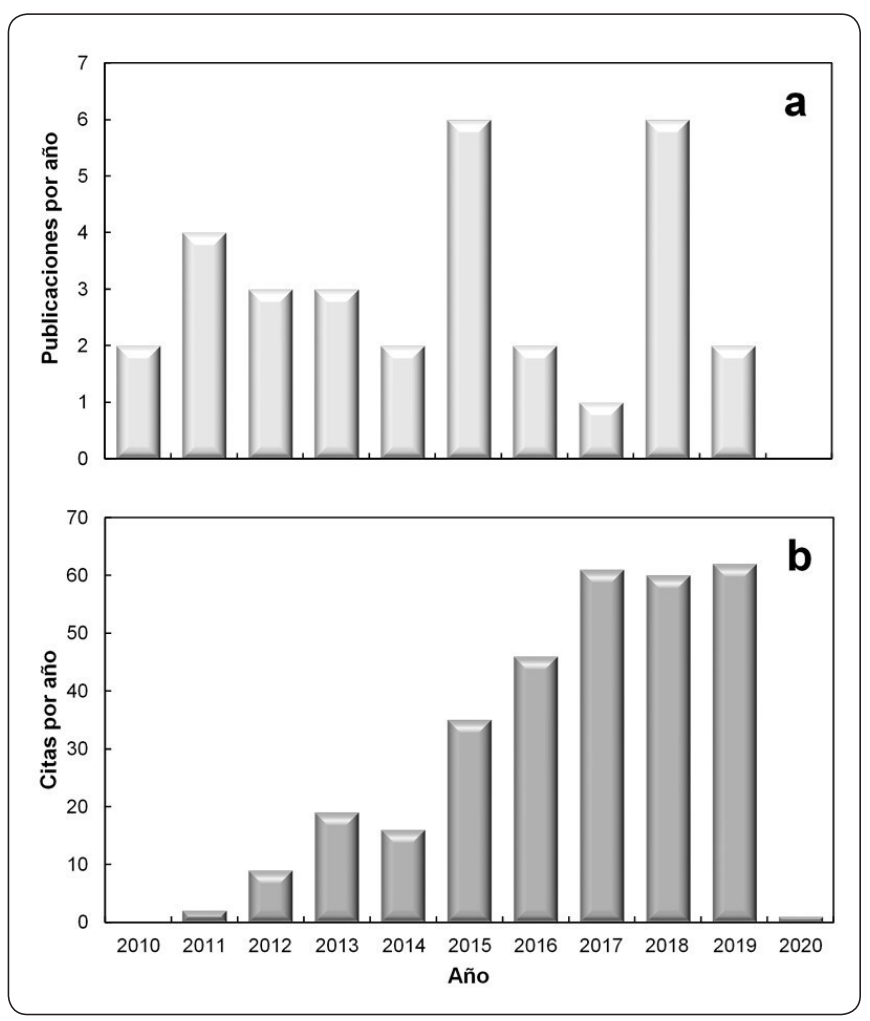

Figura 4. Número de publicaciones (a) y citas por año (b), en los últimos 10 años de los artículos científicos publicados sobre fitorremediación de suelos contaminados con DDT, encontradas en la Web of Science, revisada el 6 de marzo de 2021.

y los cuerpos de aguas contaminadas con este insecticida o sus metabolitos (DDE y DDD). Una de las plantas de mayor estudio para su aplicación en la fitorremediación es Cucurbita pepo (Whitfield Åslund, Lunney, Rutter \& Zeeb, 2010; Lunney, Rutter \& Zeeb, 2010; Paul, Rutter \& Zeeb, 2015; Eevers, Hawthorne, White, Vangronsveld \& Weyens, 2016; Eevers, Hawthorne, White, Vangronsveld \& Weyens, 2018), cuyas variedades tienen la capacidad de crecer en suelos contaminados con hasta 1,500 $\mu \mathrm{g}$ DDT $/ \mathrm{kg}$ suelo, y de fitoextraer y acumular este contaminante entre 290 y 2,600 $\mu \mathrm{g}$ DDT/kg de tejido (Whitfield Åslund et al., 2010). Además, la capacidad de C. pepo para acumular DDT puede ser modificada al variar la disponibilidad de la materia orgánica en un suelo contaminado, lo anterior debido al incremento en la biodisponibilidad del contaminante (Lunney et al., 2010). Por otro lado, se ha evaluado el potencial de plantas de marismas saladas (Scirpus maritimus, Juncus maritimus y Halimione portalacoides) para favorecer la remediación de DDT y sus metabolitos en estuarios salinos y sedimentos contaminados en Portugal; sin embargo, estas plantas no redujeron los niveles y la distribución del DDT en las zonas estudiadas (Carvalho, Rodrigues, Evangelista, Basto \& Vasconcelos, 2011).

La constante utilización de agroquímicos en los cultivos ha derivado en la contaminación de los suelos con compuestos 
como DDT y metales/metaloides pesados como arsénico (As), cobre $(\mathrm{Cu})$, plomo $(\mathrm{Pb})$, cadmio $(\mathrm{Cd})$ y otros (Huang et al., 2011; Fang et al., 2012). El DDT y el Cd pueden ser captados en diferentes concentraciones por varios genotipos de Ricinus communis, lo que es atribuible a su rápido crecimiento y a la alta absorción y acumulación de los contaminantes (Huang et al., 2011).

La contaminación por DDT también ha sido resultado de la producción y almacenamiento del insecticida (Nurzhanova et al., 2013; Younas et al., 2013), donde las concentraciones de DDT son superiores a las permitidas en los estándares sanitarios, por lo que se ha buscado utilizar la fitorremediación como estrategia para recuperar estos sitios. Las especies de plantas silvestres y de malezas que crecen en suelos contaminados proveen un recurso de especies tolerantes a condiciones adversas que pueden utilizarse en la fitorremediación. A partir de esos sitos se pueden identificar y colectar plantas capaces de remover, acumular y degradar plaguicidas organoclorados (Nurzhanova et al., 2013).

El éxito de la fitorremediación está condicionado por factores como la disponibilidad y toxicidad de los compuestos contaminantes, así como de la capacidad de las especies vegetales para removerlos o degradarlos, y de las condiciones ambientales (Mitton et al., 2014). Por lo anterior, algunos estudios evaluaron el potencial de diferentes plantas (tomate, girasol, soya y alfalfa) para limpiar suelos con muchos años de contaminación por DDT y sus metabolitos (p'p-DDT y p'p-DDE, 63.5 y 455.3 $\mu \mathrm{g} / \mathrm{kg}$ suelo, respectivamente). Después del tiempo de cultivo, la concentración de DDT disminuyó por efecto de las raíces y la actividad microbiana en la rizosfera, provocando cambios físicos y químicos en el suelo, principalmente con los cultivos de soya y tomate. Los factores de bioconcentración de DDT en la raíz del tomate fueron mayores a 1, y no se observaron síntomas de estrés oxidativo, por lo que esta especie se propuso para la fitorremediación de suelos contaminados con DDT (Mitton et al., 2014).

Los estudios in situ ayudan para identificar plantas con potencial fitorremediador porque proporcionan información en condiciones naturales; por ejemplo, Paul et al. (2015) realizaron un estudio en tres áreas del Parque Nacional de Point Pelle, Leamington, Ontario, contaminadas con diferentes concentraciones de DDT baja, moderada y alta (0.192, 291 y $5,083 \mu \mathrm{g} / \mathrm{kg}$, respectivamente). Las plantas utilizadas fueron Cucurbita pepo cv Howden y tres gramíneas nativas Schizachyrium scoparium (Michx.) Nash, Panicum virgatum L. y Sporobolus cryptandrus (Torr.)A.; de estas especies $P$. virgatum y $S$. scoparium mostraron alto potencial para la fitoextracción de DDT, incluso mayor que el encontrado en $C$. pepo.

La utilización de cualquier tipo de tecnología para remediar un sitio contaminado requiere de un análisis que considere el tipo de contaminantes, las características del sitio, y las condiciones ambientales, así como el tiempo y costos de recuperación (Chattopadhyay \& Chattopadhyay, 2015). La fitorremediación es una de las estrategias más económicas para la recuperación de cualquier sitio; un análisis sobre el costo de la fitorremediación realizado con el software Ingeniería de Acción en Costos y Requisitos para Remediación (RACER, por sus siglas en inglés), mostró que el costo de esta estrategia oscila entre 21.5 y 75.3 dólares $/ \mathrm{m}^{2}$, dependiendo del área de contaminación y características del sitio (extensión, accesibilidad al sitio, entre otros) (Chattopadhyay \& Chattopadhyay, 2015).

Las plantas tienen un sistema enzimático complejo que les permite desarrollarse aún en condiciones de diferentes tipos de estrés, ya sea hídrico, por sequía, salinidad o contaminantes. Estas condiciones de estrés pueden tener un efecto tóxico en el metabolismo vegetal. El sistema enzimático incluye enzimas antioxidantes y enzimas implicadas en la degradación de compuestos orgánicos persistentes. El conocimiento sobre el comportamiento del sistema enzimático de las plantas puede servir para proponer alguna estrategia de recuperación de sitios contaminados con compuestos como el DDT y sus metabolitos, además de proporcionar información sobre el transporte y el destino final de los contaminantes en la naturaleza.

La determinación del potencial antioxidante de las plantas tolerantes al DDT para su uso en fitorremediación se ha examinado en alfalfa y soya (Mitton, Ribas-Ferreira, Gonzalez, Miglioranza \& Monserrat, 2016), y en tomate y calabacín (Mitton, Gonzalez, Monserrat \& Miglioranza, 2018). La respuesta antioxidante es dependiente de la especie vegetal, la concentración de los contaminantes y las condiciones de cultivo. En el caso de la alfalfa y la soya, el DDT no tuvo efecto sobre los pigmentos fotosintéticos, pero sí lo tuvo en el contenido proteico, la capacidad antioxidante, la actividad glutatión s-transferasa (GST) y los grupos tioles en raíces, tallos y hojas, donde se observó disminución. La soya fue más susceptible al DDT, con disminución en la respuesta de la actividad GST y baja acumulación de DDT (Mitton et al., 2016). En las plantas de tomate y calabacín, el DDT incrementó significativamente las actividades de las enzimas catalasa, glutatión reductasa y glutatión peroxidasa; disminuyendo $(\sim 50 \%)$ la actividad GST por exposición a 63.5-101.3 $\mu \mathrm{g}$ de DDT/ $\mathrm{kg}$ suelo (Mitton et al., 2018).

Existen estudios básicos de laboratorio realizados en sistemas modelo para evaluar el potencial de fitorremediación de diversas plantas. Una de las plantas estudiada en condiciones in vitro fue Helianthus annuus L. (girasol), planta de gran adaptabilidad a condiciones adversas, que fue expuesta a 24 plaguicidas, incluyendo al DDT, y se observó mayor acumulación de los contaminantes en raíz, y $87 \%$ de remoción de los plaguicidas (de Almeida et al., 2018). 
Otros estudios sobre fitorremediación de suelos contaminados con DDT y metales pesados se han realizado con plantas consideradas como medicinales (Allium sativum L., Aloe vera L., Asparagus racemosus L., Azadirachta indica L., Bacopa monnieri L., Calotropis gigantean L., Cannabis sativa L., Catharanthus roseus L., Curcuma longa L., Datura stramonium L., Eclipta prostrate L., Hibiscus sinensis L., Lantana camara L., Ocimum tenuiflorum L., Rauvolfia serpentine L., Rosa rubiginosa L., Solanum nigrum L., Tagetes patula L., Tinospora cordifolia L. y Withania somnifera L.), ya que en condiciones naturales, la contaminación de suelos representa un riesgo a la salud de personas que utilizan este tipo de plantas, en las que se han encontrado desde 10 hasta $385,150 \mu \mathrm{g} / \mathrm{kg}$ de metales (cobre, cadmio, cromo, hierro y plomo), y entre 630 a 7,140 $\mu \mathrm{g} /$ $\mathrm{kg}$ de DDT. Este tipo de resultados demuestran que las plantas medicinales acumulan elementos potencialmente tóxicos (plomo y cromo) en concentraciones mayores a los límites permisibles establecidos por la OMS, lo que indica que se debe de vigilar la calidad de las mismas para uso medicinal y evitar exposiciones crónicas en humanos; aun cuando éstas tienen potencial para la fitorremediación se debe evitar su uso para consumo humano (Kumar et al., 2018).

La fitorremediación es una tecnología que también se ha propuesto para limpiar cuerpos de agua contaminados con compuestos orgánicos persistentes. Siguiendo los preceptos de esta tecnología, se ha propuesto y aprovechado el uso del alga verde-azul Arthrospira platensis, ya que tiene la capacidad de remover 2,3,6-trinitrotolueno (TNT), iones de cesio y DDT $(54200,90100$ y $9030 \mu \mathrm{g} / \mathrm{kg}$ ) (Tabagari et al., 2019).

\section{FITORREMEDIACIÓN ASISTIDA: CASOS DE ESTUDIO}

Puesto que la contaminación de los suelos agrícolas con DDT va acompañada de elementos potencialmente tóxicos, representa un riesgo mayor para la seguridad alimentaria y para la salud humana, por lo que la fitorremediación asistida por microorganismos es una opción para recuperar suelos contaminados. El uso de plantas hiperacumuladoras de metales (Sedum alfredii Hance) inoculadas con Sphingobacterium sp. cepa D-6 para la fitorremediación de un suelo contaminado con DDT y Cd, demuestra que la vida media de degradación del DDT (346.5 días) disminuye hasta 68\% en los tratamientos con la cepa D-6 (Fang et al., 2012). La inoculación de la bacteria Sphingobacterium sp. cepa D-6 también disminuyó la absorción del DDT, e incrementó la acumulación de $\mathrm{Cd}$ en la planta, disminuyendo el contenido de $\mathrm{Cd}$ en el suelo (hasta $58 \%$ ). Lo anterior podría deberse a que la cepa D-6 tiene la capacidad de utilizar el DDT como fuente de carbono y energía, lo que le permitió proliferar sustancialmente e incrementar la biodisponibilidad del Cd. Algunos estudios encuentran que los microorganismos pueden modificar la biodisponibilidad de los metales pesados (por inmovilización o solubilización) mediante la acidificación del ambiente, lo que cambia la especiación de los metales.
La inoculación de microorganismos en sitios contaminados también puede modificar/estimular las poblaciones microbianas que pudieran contribuir a la degradación de compuestos como el DDT, lo que se puede medir a través del índice Simpson y la tasa de respiración en el suelo (Fang et al., 2012). Lo anterior podría ser resultado de la combinación o acoplamiento de las actividades enzimáticas de la planta y los microorganismos inoculados y nativos, provocando un efecto sinérgico que incrementa la biodegradación del DDT.

La fitorremediación también puede ser asistida por compuestos químicos que promueven la disponibilidad de los contaminantes, lo que ofrece una estrategia para mejorar la recuperación de suelos contaminados. En suelos contaminados con DDT y DDE (101.3 y $381.4 \mathrm{ng} / \mathrm{g}$, respectivamente) en los que se plantó Salix sp., y con la adición de Tween 80 más ácido oxálico incrementó la desorción de los contaminantes (Mitton, Gonzalez, Peña \& Miglioranza, 2012), relacionando la reacción con el aumento del carbono orgánico cuantificado. Las plantas de Salix sp. acumulan DDT y DDE de manera natural, y esta capacidad mejora con la adición de ácido oxálico, lo que se refleja en el incremento de los factores de traslocación para ambos compuestos.

Por otra parte, Rissato et al. (2015) proponen a $R$. communis, para su uso en la fitorremediación de suelos contaminados con DDT, hexaclorociclohexano, heptaclor, aldrín y otros POP, al encontrar que cuando aumenta la hidrofobicidad de los compuestos y su interacción con la matriz del suelo, la tendencia de los compuestos a concentrarse en el tejido radical es mayor. Además, sembrar plantas en sitios contaminados modifica la microbiota del suelo(Rissato et al., 2015), generando una bioestimulación de microorganismos degradadores de contaminantes. Al respecto, Sun et al. (2015) observaron que la introducción de plantas de Orychophragmus violaceus en sedimentos contaminados con plaguicidas incrementa la degradación del hexaclorociclohexano $(\mathrm{HCH})$ hasta en un $81.2 \%$, y la degradación de DDT hasta en un $85.4 \%$, en cuanto al mesocosmos. Además, la composición, estructura y diversidad de las comunidades microbianas se modificaron en función de la remediación, encontrando una correlación entre la abundancia del gen $\operatorname{lin} \mathrm{A}$ y la remoción del $\mathrm{HCH}$, de igual manera entre la degradación de la relación HCH/DDT y la abundancia de ensamblajes de Gammaproteobacterias y Flavobacterias. Lo anterior ofrece información sobre la ecología microbiana y la modificación de los patrones entre planta-microorganismo para nuevas estrategias de biorremediación que pueden ser aplicados in situ.

La bioacumulación del DDT y sus metabolitos en los productos de la cadena alimentaria ha ayudado a proponer plantas como Cucurbita pepo ssp. pepo, para la fitorremediación de suelos contaminados. El uso de bacterias endófitas asociadas a estas plantas puede tener un papel importante en los procesos de remediación. Eevers et al. (2016) demostraron que la 
abundancia de bacterias totales y de bacterias endófitas cultivables se modifica en presencia del DDE. Los géneros Stenotrophomonas sp. y Sphingomonas sp. aumentan en cultivos de C. pepo, mientras que las bacterias del género Pseudomonas sp. disminuyen su abundancia en presencia del contaminante. Lo anterior da la pauta para utilizar bacterias endófitas en la fitorremediación asistida. La asociación de Festuca arundinacea y Lolium perenne con Pseudomonas sp. cepa BS productora de biosurfactantes incrementó la biodisponibilidad del DDT, provocando la disminución del contaminante (de 59.4 hasta 69.0\%). Además, esta asociación modificó la comunidad microbiana favoreciendo a Proteobacterias, Acidobacterias y Actinobacterias (Wang et al., 2017), este es un ejemplo de que la fitorremediación asistida por microorganismos tiene como consecuencia la bioaumentación de microorganismos con características que favorecen la degradación, en este caso del DDT. Por otro lado, el aprovechamiento de Stenotrophomonas sp. cepa DXZ9 y L. perenne garantiza hasta el $81 \%$ de la remoción de DDT y el 55\% de DDE. El DDT es declorado mediante una reducción a DDD, y deshidroclorado a DDE en el suelo (Xie, Zhu \& Wang, 2018).

La adición de oligosacáridos cíclicos como la hidroxipropilb-ciclodextrina (HPbCD) a gramíneas nativas (Schizachyrium scoparium y Panicum virgatum) de sitios contaminados con DDT, promueve la fitoextracción de este insecticida al incrementar la solubilidad del compuesto (Dahmer, Rutter \& Zeeb, 2018). No obstante, la utilización de cualquier compuesto químico para favorecer la solubilidad del DDT debe también considerar la posibilidad de aumentar la lixiviación del contaminante y provocar con ello, la contaminación de cuerpos de agua subterráneos.
Uno de los metabolitos más abundantes y recalcitrantes del DDT es el DDE que se encuentra muy presente en los suelos $(149.65 \mu \mathrm{g} / \mathrm{kg}$ ) y en cuerpos de agua. Las plantas de Cucurbita реро ssp. pepo han demostrado tener la capacidad de acumular DDE y han sido propuestas para la fitorremediación de suelos contaminados. La inoculación de estas plantas con las cepas Sphingomonas taxi UH1, Methylobacterium radiotolerans UH1, Enterobacter aerogenes UH1 (bacterias endófitas promotoras del crecimiento vegetal) o el consorcio bacteriano, no mostraron un efecto sobre la acumulación del metabolito del DDT en las plantas; sin embargo, la inoculación de $S$. taxi $\mathrm{UH} 1, M$. radiotolerans UH1 o el consorcio incrementó el peso seco vegetal. Cabe destacar que la cantidad del metabolito del DDT acumulada por $C$. pepo durante la etapa de crecimiento incrementó significativamente con la inoculación del consorcio bacteriano (Eevers et al., 2018).

La mayoría de los sitios estudiados, en los documentos científicos revisados, excedieron las concentraciones de DDT permisibles por los sectores que regulan los parámetros del contaminante (Tabla III), lo que indica una alta persistencia de éste y un reciente uso del compuesto. Como se puede observar (Tabla III), en los últimos diez años, en México aún no se consideraba la fitorremediación para la limpieza de los suelos contaminados con DDT, por lo que resulta importante comenzar a incursionar en la investigación sobre el tema y proveer a la comunidad de una estrategia para recuperar los sitios contaminados con este compuesto, que se sigue utilizando, como se mencionó, de manera clandestina.

Para limpiar un suelo contaminado se deben de considerar varios factores entre los que se incluyen: la concentración del

Tabla III. Reportes de diferentes estudios de las concentraciones y metabolitos del DDT y metales pesados.

\begin{tabular}{|c|c|c|c|c|c|c|}
\hline Compuestos & $\begin{array}{c}\text { Concentración } \\
(\mu \mathrm{g} / \mathrm{kg})\end{array}$ & Matriz & $\begin{array}{l}\text { Tiempo del } \\
\text { tratamiento } \\
\text { (días) }\end{array}$ & $\begin{array}{c}\text { Remoción } \\
(\%)\end{array}$ & Sitios de muestreo & $\begin{array}{c}\text { Referencias } \\
\text { bibliográficas }\end{array}$ \\
\hline \multicolumn{7}{|c|}{ Fitorremediación } \\
\hline$\sum \mathrm{DDT}$ & 1,730 & Suelo & 42 & ++ & $\begin{array}{l}\text { Kittigazu, Ártico } \\
\text { Canadiense }\end{array}$ & $\begin{array}{l}\text { Whitfield Åslund } \\
\text { et al., } 2010\end{array}$ \\
\hline$\sum \mathrm{DDT}$ & 1,100 & Suelo & 45 & ++ & $\begin{array}{l}\text { Kittigazu, Ártico } \\
\text { Canadiense }\end{array}$ & Lunney et al., 2010 \\
\hline$\sum \mathrm{DDT}$ & 14.74 & Sedimento & + & $\sim 51$ & $\begin{array}{l}\text { Estuario del río } \\
\text { Duero, Portugal }\end{array}$ & $\begin{array}{l}\text { Carvalho et al., } \\
2011\end{array}$ \\
\hline $\begin{array}{l}\sum \mathrm{DDT} \\
\mathrm{Cd}\end{array}$ & $\begin{array}{l}2,050 \\
3,220 \\
\end{array}$ & Suelo & 60 & ++ & \begin{tabular}{|l|} 
Cixi, Provincia de \\
Zhejiang, China \\
\end{tabular} & Huang et al., 2011 \\
\hline $\begin{array}{l}\text { DDT } \\
\text { DDE }\end{array}$ & $\begin{array}{l}4,187 \\
1,869 \\
\end{array}$ & Suelo & 180 & ++ & Karasai, Kazajstán & $\begin{array}{l}\text { Nurzhanova et al., } \\
2013\end{array}$ \\
\hline$\sum \mathrm{DDT}$ & $2,800-631,300$ & Suelo & + & ++ & $\begin{array}{l}\text { Amman Garh, } \\
\text { Pakistán }\end{array}$ & Younas et al., 2013 \\
\hline
\end{tabular}




\begin{tabular}{|c|c|c|c|c|c|c|}
\hline Compuestos & $\begin{array}{c}\text { Concentración } \\
(\mu \mathrm{g} / \mathrm{kg})\end{array}$ & Matriz & $\begin{array}{l}\text { Tiempo del } \\
\text { tratamiento } \\
\text { (días) }\end{array}$ & $\begin{array}{c}\text { Remoción } \\
(\%)\end{array}$ & Sitios de muestreo & $\begin{array}{c}\text { Referencias } \\
\text { bibliográficas }\end{array}$ \\
\hline $\begin{array}{l}\text { DDT } \\
\text { DDE }\end{array}$ & $\begin{array}{c}63.5 \\
455.3\end{array}$ & Suelo & 15 y 60 & ++ & $\begin{array}{l}\text { Villa Regina, Cuenca } \\
\text { del Río Negro, } \\
\text { Argentina }\end{array}$ & $\begin{array}{l}\text { Mitton et al., 2014; } \\
\text { Mitton et al., 2016; } \\
\text { Mitton et al., 2018 }\end{array}$ \\
\hline DDT & $0.192-5,083$ & Suelo & + & ++ & $\begin{array}{l}\text { Leamington Ontario, } \\
\text { Canadá }\end{array}$ & Paul et al., 2015 \\
\hline DDT & 10 & $\begin{array}{l}\text { Biomasa de } \\
\text { plantas }\end{array}$ & 60 & $\sim 95$ & Cultivo in vitro & $\begin{array}{l}\text { de Almeida et al., } \\
2018\end{array}$ \\
\hline $\begin{array}{l}\text { DDT } \\
\text { TNT } \\
\text { Iones de } \\
\text { cesio }\end{array}$ & $\begin{array}{c}10,000 \\
22,500-56,000 \\
100,000\end{array}$ & Agua* & 7 & 90 & Georgia, E. U. & $\begin{array}{l}\text { Tabagari et al., } \\
2019\end{array}$ \\
\hline \multicolumn{7}{|c|}{ Fitorremediación asistida } \\
\hline $\begin{array}{l}\sum \mathrm{DDT} \\
\mathrm{Cd}\end{array}$ & $\begin{array}{l}350 \\
300\end{array}$ & Suelo & $\begin{array}{l}30,60,90 \\
150 \text { y } 210\end{array}$ & $60-95$ & $\begin{array}{l}\text { Cixi, Provincia de } \\
\text { Zhejiang, China }\end{array}$ & Fang et al., 2012 \\
\hline $\begin{array}{l}\text { DDT } \\
\text { DDE } \\
\text { DDD }\end{array}$ & $\begin{array}{c}101.3 \\
381.4 \\
0.4\end{array}$ & Suelo & 40 & $60-90$ & $\begin{array}{l}\text { Villa Regina, Cuenca } \\
\text { del Río Negro, } \\
\text { Argentina }\end{array}$ & Mitton et al., 2012 \\
\hline$\sum \mathrm{DDT}$ & 1,417 & Suelo & 100 & 65.9 & $\begin{array}{l}\text { Provincia de Henan, } \\
\text { China }\end{array}$ & Wang et al., 2017 \\
\hline$\sum \mathrm{DDT}$ & 31,000 & Suelo & 91 & 55 & $\begin{array}{l}\text { Parque Nacional } \\
\text { Pelee, Leamington, } \\
\text { Ontario, Canadá }\end{array}$ & $\begin{array}{l}\text { Dahmer et al., } \\
2018\end{array}$ \\
\hline $\begin{array}{l}\text { DDT } \\
\text { DDE }\end{array}$ & $\begin{array}{l}2,230 \\
1,260\end{array}$ & Suelo & 210 & $\begin{array}{l}81 \\
55\end{array}$ & $\begin{array}{l}\text { Campus Sur, } \\
\text { Universidad Agrícola } \\
\text { de Shandong, } \\
\text { Taiwan, China }\end{array}$ & Xie et al., 2018 \\
\hline DDE & 149.65 & Suelo & 100 & $\sim 100$ & $\begin{array}{l}\text { Lockwood Farm, } \\
\text { Connecticut } \\
\text { Estación } \\
\text { Experimental de } \\
\text { Agricultura USA }\end{array}$ & Eevers et al., 2018 \\
\hline
\end{tabular}

$\sum \mathrm{DDT}=$ 4,4'-DDT, 2,4'-DDT, 4,4'-DDD, 2,4'-DDD, 4,4'-DDE, 2,4'-DD. Límites máximos permisibles WHO (2007): $\sum \mathrm{DDT}=100$; Fe=20,000; $\mathrm{Cu}=150,000 ; \mathrm{Cd}=300 ; \mathrm{Pb}=10,000 ; \mathrm{Cr}=2,000 \mu \mathrm{g} / \mathrm{kg}$. Límites máximos permisibles Romero, Cortinas \& Gutiérrez (2009): $\sum \mathrm{DDT}=140 \mu \mathrm{g} / \mathrm{kg}$. *Contaminación artificial.+ Tiempo no especificado por ser plantas nativas, cosechadas para determinar la acumulación de DDT en los tejidos. ++ Limitados a reportar lo acumulado en las plantas 
contaminante, el tiempo que tiene contaminado el sitio; las características del suelo y las interacciones que existen entre el suelo y el contaminante; la toxicidad del contaminante, así como la capacidad de las especies vegetales para removerlos o degradarlos, por todo esto en los estudios de fitorremediación los tiempos de experimentación varían (Tabla III) (Mitton et al., 2014; Chattopadhyay \& Chattopadhyay, 2015). Sin embargo, la fitorremediación ofrece la ventaja de ser económica y rápida, a diferencia de estrategias en las que se utilizan productos químicos, que modifican drásticamente las propiedades del suelo dejándolo infértil para su reutilización con fines de cultivo (Chattopadhyay \& Chattopadhyay, 2015). Al acumular las plantas los compuestos tanto en raíces como en tallos, es importante analizar los tejidos vegetales, con la finalidad de saber cómo se les utilizará en la fitorremediación.

\section{CONCLUSIONES Y PERSPECTIVAS}

Las concentraciones de DDT en los sitios donde se evaluó la fitorremediación son muy variables y exceden los límites permisibles por los sectores de salud de cada región, los artículos científicos demuestran que la fitorremediación es una tecnología que se puede utilizar como estrategia para recuperar suelos y aguas contaminadas con DDT y metales pesados. Existen diferentes plantas con capacidad fitorremediadora, destacando plantas comestibles como calabaza, tomate, soya, calabacín, otras como gramíneas, plantas de ornato, algas, árboles, y plantas consideradas medicinales. Todas estas plantas tienen la capacidad de acumular el DDT en tallos y en raíces. El éxito de la fitorremediación depende de factores como las condiciones ambientales, la concentración de los contaminantes, las plantas seleccionadas y el tipo de contaminante, por lo que es necesario realizar un análisis detallado del sitio antes de la implementación de la fitorremediación.

La fitorremediación asistida por microorganismos para sitios contaminados con DDT mejora significativamente la remoción del mismo y de los metales pesados, por lo que su uso incrementaría el éxito en la restauración de suelos contaminados que podrían ser utilizados nuevamente y de manera segura en la agricultura.

Durante los últimos diez años en México no se han considerado los estudios de fitorremediación para la limpieza de los suelos contaminados con DDT, por lo que resulta importante continuarlos para ofrecer a las comunidades una estrategia económica con la recuperación de los sitios contaminados con este compuesto, que se sigue utilizando de manera clandestina en el país.

La gran aceptación del DDT hace que se siga utilizando en la agricultura y de forma regulada por el sector salud para el control de vectores transmisores de enfermedades como malaria, paludismo y dengue. Sin embargo, existen otras alternativas para el control de estos vectores, como son los piretroides, compuestos que han tenido gran aceptación para su uso, aunque también representan un riesgo potencial para la salud humana, por lo que es necesario, evaluar su toxicidad y persistencia en los sistemas donde se aplican, para evitar daños como los que causa el DDT.

\section{Agradecimientos}

Caliope Mendarte-Alquisira agradece al CONACYT el apoyo otorgado durante la estancia posdoctoral en la que se desarrolló la escritura de la presente revisión y a los revisores sus valiosos comentarios para mejorar el manuscrito.

\section{CONFLICTO DE INTERESES}

Los autores declaramos que no existe conflicto de intereses.

\section{REFERENCIAS}

Al-Baldawi, I.A., Abdullah, S.R.S., Anuar, N., Suja, F. \& Mushrifah, I. (2015). Phytodegradation of total petroleum hydrocarbon (TPH) in diesel-contaminated water using Scirpus grossus. Ecological Engineering, 74, 463-473. https://doi.org/10.1016/j.ecoleng.2014.11.007

Arrebola, J.P., Fernández, M.F., Olea, N., Ramos, R. \& Martin-Olmedo, P. (2013). Human exposure to $p, p$ 'dichlorodiphenyldichloroethylene ( $p, p$ '-DDE) in urban and semi-rural areas in southeast Spain: A gender perspective. Science of the Total Environment, 458-460, 209-216. http:// dx.doi.org/10.1016/j.scitotenv.2013.04.001

Bornman, R., Jager, C., Worku, Z., Farias, P. \& Reif, S. (2010). DDT and urogenital malformations in newborn boys in a malarial area. BJU International, 106(3), 405-411. https:// doi.org/10.1111/j.1464-410X.2009.09003.x

Carvalho, P.N., Rodrigues, P.N.R., Evangelista, R., Basto, M.C.P. \& Vasconcelos, M.S.D. (2011). Can salt marsh plants influence levels and distribution ofDDTs in estuarine areas? Estuarine Coastal and ShelfScience, 93(4), 415-419. https://doi.org/10.1016/j.ecss.2011.05.008

Chávez-Almazán, L.A., Díaz-Ortiz, J.A., Saldarriafa-Noreña, H.A., Dávila-Vázquez, G., Santiago-Moreno, A., RosasAcevedo, J.L., Sampedro-Rosas, M.L., López-Silva, S. \& Waliszewski, S.M. (2018). Análisis regional de la contaminación por pesticidas organoclorados en la leche humana en Guerrero, México. Revista Internacional de Contaminación Ambiental, 34(2), 225-235. https://doi. org/10.20937/RICA.2018.34.02.04

Chattopadhyay, S. \& Chattopadhyay, D. (2015). Remediation of DDT and its metabolites in contaminated sediment. Current Pollution Reports, 1, 248-264. https://doi.org/10.1007/ s40726-015-0023-z

Chlebek, D. \& Hupert-Kocurek, K. (2019). Endophytic bacteria in the phytodegradation of persistent organic pollutants. Postepy Mikrobiologii, 58(1), 70-79. https:// doi.org/10.21307/PM-2019.58.1.070

Cohn, B.A., Cirillo, P.M. \& Terry, M.B. (2019). DDT and breast cancer: Prospective study of induction time and 
susceptibility windows. Journal of the National Cancer Institute, 111(8), djy198. https://doi.org/10.1093/jnci/ djy198

Cunningham, S.D., Berti, W.R. \& Huang, J.W. (1995). Phytoremediation of contaminated soils. Environmental Biotechnology, 13(9), 393-397. https://doi.org/10.1016/ S0167-7799(00)88987-8

Cupul-Uicab, L.A., Bornman, R., Archer, J.I., Kudumu, M.O., Travlos, G.S., Wilson, R.E. \& Whitworth, K.W. (2020). Exposure to DDT from indoor residual spraying and biomarkers of inflammation among reproductive-aged women from South Africa. Environmental Research. 191, 110088. https://doi.org/10.1016/j.envres.2020.110088

Dahmer, C.P., Rutter, A. \& Zeeb, B. (2018). The fate of DDT in soil treated with hydroxypropyl- $\beta$-cyclodextrin (HP $\beta C D)$. International Journal of Phytoremediation, 20(6), 5234529. https://doi.org/10.1080/15226514.2017.1393389

de Almeida, M.V., Rissato, S.R., Galhiane, M.S., Fernandes, J.R., Lodi, P.C. \& de Campos, M.C. (2018). In vitro phytoremediation of persistent organic pollutants by Helianthus annuus L. plants. Quimica Nova, 41(3), 251-257. http://dx.doi.org/10.21577/0100-4042.20170177

De la Rosa-Pérez, D.A., Teutli-León, M.M.M. \& RamírezIslas, M.E. (2007). Electrorremediación de suelos contaminados, una revisión técnica para su aplicación en campo. Revista Internacional de Contaminación Ambiental, 23(3), 129-138. http://www.scielo.org.mx/ pdf/rica/v23n3/v23n3a3.pdf

Díaz-Barriga, M.F., Trejo-Acevedo, A., Betanzos, A.F., Espinosa-Reyes, G., Alegría-Torres, J.A. \& Pérez, M.I.N. (2012). Assessment of DDT and DDE levels in soil, dust, and blood samples from Chihuahua, Mexico. Archives of Environmental Contamination and Toxicology, 62(2), 351358. http://doi.org/10.1007/s00244-011-9700-0

Eevers, N., Hawthorne, J.R., White, J.C., Vangronsveld, J. \& Weyens, N. (2016). Exposure of Cucurbita pepo to DDE-contamination alters the endophytic community: A cultivation dependent vs a cultivation independent approach. Environmental Pollution, 209, 147-154. http:// dx.doi.org/10.1016/j.envpol.2015.11.038

Eevers, N., Hawthorne, J.R., White, J.C., Vangronsveld, J. \& Weyens, N. (2018). Endophyte-enhanced phytoremediation of DDE-contaminated using Cucurbita pepo: A field trial. International Journal of Phytoremediation, 20(4), 301-310. https://doi.org/10.1080/15226514.2017.1377150

Fang, H., Zhou, W., Cao, Z., Tang, F., Wang, D., Liu, K., Wu, X., Yang, X., Sun, Y. \& Yu, Y. (2012). Combined remediation of DDT congeners and cadmium in soil by Sphingobacterium sp. D-6 and Sedum alfredii Hance. Journal of Environmental Sciences, 24(6), 1036-1046. https://doi.org/10.1016/S10010742(11)60895-4

Farraji, H., Zaman, N.Q., Tajuddin, R.M. \& Faraji, H. (2016). Advantages and disadvantages of phytoremediation: A concise review. International Journal of Environmental
Science and Technology, 2, 69-75. https://www. researchgate.net/publication/306543535_Advantages _ and_disadvantages_of_phytoremediation_A_concise_ review

Fernícola, N.A.G.G. (1985). Toxicidad de los insecticidas organoclorados. Boletín de la Oficina Sanitaria Panamericana. 98(1), 10-20. https://iris.paho.org/ bitstream/handle/10665.2/16966/v98n1p10. pdf? sequence $=1 \&$ isAllowed $=\mathrm{y}$

Fiedler, H. (2007). National PCDD/PCDF release inventories under the Stockholm Convention on persistent organic pollutants. Chemosphere, 67(9), 96-108. https://doi. org/10.1016/j.chemosphere.2006.05.093

Gamboa, F.N. (2014). DDT, una revisión histórica. Revista de Química PUCP, 28(1), 10-13. http://revistas.pucp.edu.pe/ index.php/quimica/article/view/10826/11327

García-de la Parra, L.M., Cervantes-Mojica, L.J., GonzálezValdivia, C., Martínez-Cordero, F.J., Aguilar-Zárate, G., Bastidas-Bastidas, P. \& Betancourt-Lozano, M. (2012). Distribution of Pesticides and PCBs in Sediments of Agricultural Drains in the Culiacan Valley, Sinaloa, Mexico. Archives of Environmental Contamination and Toxicology. 63(3), 323-36 http://doi.org/10.1007/s00244-012-9780-5

Genthe, B., LeRoux, W.J, Schachtschneider, K., Oberholster, P.J., Aneck-Hahn, N.H. \& Chamier, J. (2013). Health risk implications from simultaneous exposure to multiple environmental contaminants. Ecotoxicology and Environmental Safety, 93, 171-179. http://dx.doi. org/10.1016/j.ecoenv.2013.03.032

Giácoman-Vallejos, G., Lizarraga-Castro, I., Ponce-Caballero, C., González-Sánchez, A. \& Hernández-Núñez, E. (2018). Presence of DDT and lindane in a karstic groundwater aquifer in Yucatan, Mexico. Groundwater Monitoring \& Remediation, 38(2), 68-78. https://doi.org/10.1111/ gwmr. 12267

Glick, B.R. (2010). Using soil bacteria to facilitate phytoremediation. Biotechnology Advances, 28(3), 367374. https://doi.org/10.1016/j.biotechadv.2010.02.001

Gyalpo, T., Fritsche, L., Bouwman, H., Bornman, R., Scheringer, M. \& Hungerbühñler, K. (2012). Estimation of human body concentrations of DDT from indoor residual spraying for malaria control. Environmental Pollution, 169, 234-241. https://doi.org/10.1016/j.envpol.2012.04.032

Hancock, P.A, Wiebea, A., Gleave, K.A., Bhatt, S., Cameron, E., Trett, A., Weetman, D., Smithd, D.L., Hemingwa, J., Coleman, M., Gething, P.W. \& Moyes, C.L. (2018). Associated patterns of insecticide resistance in field populations of malaria vectors across Africa. Proceedings of the National Academy of Sciences, 115, 5938-5943. http:// www.pnas.org/cgi/doi/10.1073/pnas.1801826115

He, Y., Langenhoff, A.A.M., Sutton, N.B., Rijnaarts, H.H.M., Blokland, M.H., Chen, F., Huber, C. \& Schröder, P. (2017). Metabolism of ibuprofen by Phragmites australis: Uptake and phytodegradation. Environmental Science \& 
Technology, 51(8), 4576-4584. https://doi.org/10.1021/ acs.est. $7 \mathrm{~b} 00458$

Huang, H., Yu, N., Wang, L., Gupta, D.K., He, Z., Wang, K., Zhu, Z., Yan, X., Li, T. \& Yang, X. (2011). The phytoremediation potential of bioenergy crop Ricinus communis for DDTs and cadmio co-contaminated soil. Bioresource Technology, 102(23), 11034-11038. https:// doi.org/10.1016/j.biortech.2011.09.067

Ignatius, A., Arunbabu, V., Neethu, J. \& Ramasam, E.V. (2014). Rhizofiltration of lead using aromatic medicinal plant Plectranthus amboinicus cultured in a hydroponic nutrient film technique (NFT) system. Environmental Science and Pollution Research, 21(22), 13007-13016. https://doi. org/10.1007/s11356-014-3204-1

Kenneth Barbalace. (1995-2019). Chemical DatabaseDDT. EnvironmentalChemistry.com. https:// EnvironmentalChemistry.com/yogi/chemicals/cn/DDT. html (Consultado Noviembre 12, 2019).

Kong, Z. \& Glick, B.R. (2017). The Role of Plant GrowthPromoting Bacteria in Metal Phytoremediation. Chapter in Advances in Microbial Physiology. Advances in Microbial Physiology, 71, 97-132. http://dx.doi.org/10.1016/ bs.ampbs.2017.04.001

Kucher, S., Ricking, M. \& Schwarzbauer, J. (2019). The Effect of Environmental Processes on the Isomeric Composition ofDDT-related Compounds. Soil and Sediment Contamination: An International Journal, 28(3), 1-16. https://doi.org/10.1080/15320383.2018.1561649

Kumar, N., Kulsoom, M., Shukla, V., Kumar, D., Priyanka, Kumar, S., Tiwari, J. \& Dwivedi, N. (2018). Profiling of heavy metal and pesticide residues in medicinal plants. Environmental Science and Pollution Research, 25(29), 29505-29510 https://doi.org/10.1007/s11356-018-2993-z

Leal, S.S.D., Valenzuela, A.I., Gutiérrez, C.M. de L., Bermúdez, A.M. del C., García, H.J., Aldana, M.M.L., Grajeda, C.P., Silveira, G.M.I., Meza, M.M.M., Palma, D.S.A., Leyva, G.G.N., Camarena, G.B.O. \& Valenzuela, N.C.P. (2014). Residuos de pesticidas en suelos agrícolas. Terra Latinoamericana, 32(1), 1-11. https://www. terralatinoamericana.org.mx/index.php/terra/article/ view/14/12

Lee, J.H. (2013). An overview of phytoremediation as a potentially promising technology for environmental pollution control. Biotechnology and Bioprocess Engineering, 18,431-439. https://doi.org/10.1007/s12257013-0193-8

Lunney, A.I., Rutter, A. \& Zeeb, B.A. (2010). Effect of organic matter additions on uptake of weathered DDT by Cucurbita pepo ssp. pepo cv. Howden. International Journal of Phytoremediation, 12(4), 404-417. https://doi. org/10.1080/15226510903051773

Mahugija, J.A.M., Nambela, L. \& Mmochi, A.J. (2017). Levels and distribution of pesticide residues in soil and sediments in Eastern Lake Tanganyika environs. International Journal of Biological Sciences, 11(5), 2537-2547. https://dx.doi. org/10.4314/ijbcs.v11i5.46

Martínez-Salinas, R.I., Díaz-Barriga, F., Batres-Esquivel, L.E. \& Pérez-Maldonado, I.N. (2011). Assessment of the levels of DDT and its Metabolites in soil and dust Samples from Chiapas, Mexico. Bulletin of Environmental Contamination and Toxicology, 86, 33-37. http://doi.org/10.1007/s00128010-0174-y

Melo, D.C.A., de Souza, M.W., De Carvalho, F.P., Massenssini, A.M., da Silva, A.A., Ferreira, L.R. \& Costa, M.D. (2017). Microbial activity of soil with sulfentrazone associated with phytoremediator species and inoculation with a bacterial consortium. Soil and Plant Nutrition, 72(2), 300-310. http:// dx.doi.org/10.1590/1678-4499.203

Menn, J.J., Still, G.G. \& Ruhr, R.J. (1977). Metabolism of insecticides and herbicides in higher plants. $C R C$ Critical Reviews in Toxicology, 5(1), 1-21. https://doi. org/10.3109/10408447709101340

Mitton, F.M., Gonzalez, M., Peña, A. \& Miglioranza, K.S.B. (2012). Effects of amendments on soil availability and phytoremediation potential of aged $p, p^{\prime}$-DDT. $p, p$ '-DDE and $p, p$ '-DDD residues by willow plants (Salix sp.). Journal of Hazardous Materials, 203-204, 62-68. https:// doi.org/10.1016/j.jhazmat.2011.11.080

Mitton, F.M, Miglioranza, K.S.B., González, M., Shimabukuro, V.M. \& Monserrat, J.M. (2014). Assessment of tolerance and efficiency of crop species in the phytoremediation of DDT polluted soils. Ecological Engineering, 71, 501-508. http://dx.doi.org/10.1016/j.ecoleng.2014.07.069

Mitton, F.M, Ribas, R.J.L., Gonzalez, M., Miglioranza, K.S.B. \& Monserrat, J.M.(2016). Antioxidant responses in soybean and alfalfa plants grown in DDTs contaminated soils: useful variables for selecting plants for soil phytoremediation? Pesticide Biochemistry and Physiology, 130, 17-21. http:// dx.doi.org/10.1016/j.pestbp.2015.12.005

Mitton, F.M., Gonzalez, M., Monserrat, J.M. \& Miglioranza, K.S.B. (2018). DDTs-induced antioxidant responses in plants and their influence on phytoremediation process. Ecotoxicology and Environmental Safety, 147, 141-156. http://dx.doi.org/10.1016/j.ecoenv.2017.08.037

Mochungong, P. \& Zhu, J. (2015). DDTs, PCBs and PBDEs contamination in Africa, Latin America and South-southeast Asia - a review. AIMS Environmental Science, 2(2), 374399. https://doi.org/10.3934/environsci.2015.2.374

Munier, M., Ayoub, M., Suteau, V., Gourdin, L., Henrion, D., Reiter, E. \& Rodien, P. (2021). In vitro effects of the endocrine disruptorp, $\mathrm{p}^{\prime} \mathrm{DDT}$ on human choriogonadotropin/ luteinizing hormone receptor signalling. Archives of Toxicology, 95(5), 1-11 https://doi.org/10.1007/s00204021-03007-1

Najeeb, U., Ahmad, W., Zia, M.H., Malik, Z. \& Zhou, W. (2017). Enhancing the lead phytostabilization in wetland plant Juncus effusus L. through somaclonal manipulation and EDTA enrichment. Arabian Journal of 
Chemistry, 10(2), S3310-S3317.http://dx.doi.org/10.1016/j. arabjc.2014.01.009

Nurzhanova,A., Kalugin, S. \& Zhambakin, K. (2013). Obsolete pesticides and application of colonizing plant species for remediation of contaminated soil in Kazakhstan. Environmental Science and Pollution Research, 20, 20542063. https://doi.org/10.1007/s11356-012-1111-x

Odewale, G.O., Sosan, M.B., Oyekunle, J.A.O. \& Adeleye, A.O. (2021). Human health risk assessment of dichlorodiphenyltrichloroethane (DDT) and hexachlorocyclohexane $(\mathrm{HCH})$ pesticide residues in fruits and vegetables in Nigeria. Environmental Science and Pollution Research. https://doi.org/10.1007/s11356021-12747-7

Organización Mundial de la Salud. (2019). Pesticidas altamente peligrosos. https://www.who.int/ipcs/assessment/public health/pesticides/es/ (Consultado Octubre 16, 2019).

Paul, S., Rutter, A. \& Zeeb, B.A. (2015). Phytoextraction of DDT-contaminated soil at Point Pelee National Park, Leamington ON, using Cucurbita pepo cultivar Howden and native grass species. Journal of Environmental Quality, 44(4), 1201-1209. https://doi.org/10.2134/jeq2014.11.0465

Peng, S., Kong, D., Li, L., Zou, C., Chen, F., Li, M., Cao, T., Yu, C., Song, J., Jia, W. \& Peng, P. (2020). Distribution and sources of DDT and its metabolites in porewater and sediment from a typical tropical bay in the South China Sea. Environmental Pollution, 267, 115492. https://doi. org/10.1016/j.envpol.2020.115492

Pérez-Maldonado, I.N., Trejo, A., Ruepert, C., Jovel, R.C., Méndez, M.P., Ferrari, M., Saballos-Sobalvarro, E., Alexander, C., Yáñez-Estrada, L., Lopez, D., Henao, S., Pinto, E. R. \& Díaz-Barriga, F. (2010). Assessment of DDT levels in selected environmental media and biological samples from Mexico and Central America. Chemosphere, 78(10), 1244-1249. https://doi.org/10.1016/j. chemosphere.2009.12.040

Pilon-Smits, E. (2005). Phytoremediation. Annual Review of Plant Biology, 56, 15-39. https://doi.org/10.1146/annurev. arplant.56.032604.144214

Ponce-Vélez, G. \& Botello, E.V. (2018). Plaguicidas organoclorados en organismos costeros y marinos de los litorales mexicanos: una revisión. Revista Internacional de Contaminación Ambiental (Especial sobre Contaminación y Toxicología por Plaguicidas II), 34, 81-98. https://doi. org/10.20937/RICA.2018.34.esp02.07

Richardson, J.R., Roy, A., Shalat, S.L., Stein, R.T., Hossain, M.M., Buckley, B., Gearing, M., Levey, A. \& German, D.C. (2014). Elevated serum pesticide levels and risk for Alzheimer disease. JAMA Neurology, 71(3), 284-290. https://doi.org/10.1001/jamaneurol.2013.6030

Rissato, S.R., Galhiane, M.S., Fernandes, J.R., Gerenutti, M., Marques, G.H., Ribeiro, R. \& de Almeida, M.V. (2015). Evaluation of Ricinus communis L. for phytoremediation of polluted soil with organochlorine pesticides. BioMed Research International, 2015, 1-8 http:// dx.doi.org/10.1155/2015/549863

Robinson, B.H., Anderson, C.W.N. \& Dickinson, N.M. (2015). Phytoextraction: Where's the action? Journal of Geochemical Exploration, 151, 34-40. https://doi. org/10.1016/j.gexplo.2015.01.001

Romero, T.T., Cortinas, de N. C \& Gutiérrez, A.V.J. (2009). Diagnóstico nacional de los contaminantes orgánicos persistentes en México. Secretaria del Medio Ambiente y Recursos Naturales. Instituto Nacional de Ecología. México, D. F. https://cristinacortinas.org/sustentabilidad/ download/diagnostico-nacional-de-los-contaminantesorganicos-persistentes-en-mexico/

Sheoran, V., Sheoran, A.S. \& Poonia, P. (2016). Factors affecting Phytoextraction: A Review. Pedosphere, 26(2), 148-166. https://doi.org/10.1016/S1002-0160(15)60032-7

Silva, V., Mol, H.G.J., Zomer, P., Tienstra, M., Ritsema, C.J. \& Geissen, V. (2019). Pesticide residues in European agricultural soil-A hidden reality unfolded. Science of The Total Environment, 653, 1532-1545. https://doi. org/10.1016/j.scitotenv.2018.10.441

Sun, G., Zhang, X., Hu, Q., Zhang, H., Zhang, D. \& Li, G. (2015). Biodegradation of dichlorodiphenyltrichloroethanes (DDTs) and hexachlorocyclohexanes (HCHs) whit plants and nutrients and their effects on the microbial ecological kinetics. Microbial Ecology, 69(3), 281-292. https://doi. org/10.1007/s00248-014-0489-z

Sun, R.-X., Sun, Y., Xie, X.-D., Yang, B.-Z., Cao, L.-Y., Luo, S., Wang, Y.-Y. \& Mai, B.-X. (2020). Bioaccumulation and human health risk assessment of DDT and its metabolites (DDTs) in yellowfin tuna (Thunnus albacares) and their prey from the South China Sea. Marine Pollution Bulletin. 158, 111396. https://doi.org/10.1016/j. marpolbul.2020.111396

Suresh, B., Sherkhane, P.D., Kale, S., Eapen, S. \& Ravishankar, G.A. (2005). Uptake and degradation of DDT by hairy root cultures of Cichorium intybus and Brassica juncea. Chemosphere, 61(9), 1288-1292.https://doi.org/10.1016/j. chemosphere.2005.03.086

Sylvain, B., Mikael, M-H., Florie, M., Emmanuel, J., Marilyne, S., Sylvain, B. \& Domenico, M. (2016). Phytostabilization of $\mathrm{As}, \mathrm{Sb}$ and $\mathrm{Pb}$ by two willow species $(S$. viminalis and S. purpurea) on former mine technosols. CATENA, 136, 44-52. http://dx.doi.org/10.1016/j.catena.2015.07.008

Tabagari, I., Kurashvili, M., Varazi, T.,Adamia, G., Gigolashvili, G., Pruidze, M., Chokheli, L., Khatisashvili, G. \& Niemsdorff, P von F. (2019). Application of Arthrospira (Spirulina) platensis against chemical pollution of water. Water, 11(9), 1759. https://doi.org/10.3390/w11091759

Tarla, D.N., Erickson, L.E., Hettiarachchi, G.M., Amadi, S-L., Galkaduwa, M., Davis, L.C., Nurzhanova, A. \& Pidlisnyuk, V. (2020). Phytoremediation and Bioremediation of Pesticide-Contaminated Soil. Applied Sciences, 10(4), 1217. https://doi.org/10.3390/app10041217 
Torres-Dosal,A., Martinez-Salinas, R.I., Hernandez-Benavides, D., Perez-Vazquez, F.J., Ilizaliturri-Hernandez, C. \& PerezMaldonado, I.N. (2012). Assessment of the levels of DDT and DDE in soil and blood samples from Tabasco, Mexico. Environmental Monitoring and Assessment, 184(12), 75517559. http://doi.org/10.1007/s10661-012-2518-z

Ullah,A., Heng, S., Munis, M.F.H., Fahad, S. \& Yang, X. (2015). Phytoremediation of heavy metals assisted by plant growth promoting (PGP) bacteria: A review. Environmental and Experimental Botany, 117, 28-40. https://doi.org/10.1016/j. envexpbot.2015.05.001

UNEP. (2001). Stockholm Convention on Persistent Organic Pollutants. Revised in 2017. http://chm.pops. int/TheConvention/Overview/TextoftheConvention/ tabid/2232/Default.aspx (Consultado Octubre 8, 2019).

Van Eerd, L.L., Hoagland, R.E. \& Hall, J.C. (2003). Pesticide metabolism in plants and microorganisms. Weed Science, 51, 472-495.https://pubag.nal.usda.gov/download/48638/PDF

Velasco, A., Hernández, S., Ramírez, M. \& Ortíz, I. (2014). Detection of residual organochlorine and organophosphorus pesticides in agricultural soil in Rio Verde region of San Luis Potosi, Mexico. Journal of Environmental Science and Health, Part B: Pesticides, Food Contaminants, and Agricultural Wastes, 49(7), 498-504. http://dx.doi.org/10. 1080/03601234.2014.896670

Vizcaino, E., Grimalt, J.O., Fernández-Somoano, A. \& Tardon, A. (2014). Transport of persistent organic pollutants across the human placenta. Environment International, 65, $107-$ 115. http://dx.doi.org/10.1016/j.envint.2014.01.004

Wang, J., Feng, X., Anderson, C.W.N., Xing, Y. \& Shang, L. (2012). Remediation of mercury contaminated sites-A review. Journal of Hazardous Materials, 221-222, 1-18. http://dx.doi.org/10.1016/j.jhazmat.2012.04.035

Wang, B., Wang, Q., Liu, W., Liu, X., Hou, J., Teng, Y., Luo, Y. \& Christie, P. (2017). Biosurfactant-producing microorganism Pseudomonas sp. SB assist the phytoremediation of DDT-contaminated soil by two grass species. Chemosphere, 182, 137-142. https://doi.org/10.1016/j. chemosphere.2017.04.123

Whitfield Åslund, M.L., Lunney, A.I., Rutter, A. \& Zeeb, B.A. (2010). Effects of amendaments on the uptake and distribution of DDT in Cucurbita pepo ssp. pepo plants. Environmental Pollution, 158(2), 508-513. https://doi. org/10.1016/j.envpol.2009.08.030
Woldetsadik, D., Simon, M.P., Knuth, D., Hailu, H., Gebresilassie,A., Dejen, A. \& Düring, R-A. 2021. Exposure to DDT and $\mathrm{HCH}$ congeners and associated potential health risks through khat (Catha edulis) consumption among adults in South Wollo, Ethiopia. Environmenta Geochemistry and Health, 17, 1-17.https://doi.org/10.1007/ s10653-021-00846-w

WorldHealthOrganization.(2007).WHOGuidelinesforassessing quality of herbal medicines quality of herbal medicines with reference to contaminants and residues. https://apps.who. int/iris/bitstream/handle/10665/43510/9789241594448_ eng.pdf? sequence $=1 \&$ is Allowed $=y$

World Health Organization. (2011). Global Malaria Program. The use of DDT in Malaria Vector Control. Geneva. https://apps.who.int/iris/bitstream/handle/10665/69945/ WHO_HTM_GMP_2011_eng.pdf?sequence $=1$

Wu, H-C., Cohn, B.A., Cirillo, P.M., Santella, R M. \& Terry, M.B. (2019). DDT exposure during pregnancy and DNA methylation alterations in female offspring in the child health and development study. Reproductive Toxicology,92, 138-147. https://doi.org/10.1016/j.reprotox.2019.02.010

Xia, C., Ma, X., Liu, S. \& Fan, P. (2012). Management and Technology. Studies on remediation of DDT-contaminated soil and dechlorination of DDT. The 7 th International Conference on Waste. Procedia Environmental Sciences, 16,289-292. https://doi.org/10.1016/j.proenv.2012.10.040

Xie, H., Zhu, L. \& Wang, J. (2018). Combined treatment of contaminated soil with a bacterial Stenotrophomonas strain DXZ9 and ryegrass (Lolium perenne) enhances DDT and DDE remediation. Environmental Science and Pollution Research, 25(32), 31895-31905. https://doi.org/10.1007/ s11356-018-1236-7

Yáñez, L., Ortiz-Pérez, D., Batres, L.E., BorjaAburto, V.H. \& Díaz-Barriga, F. (2002). Levels of dichlorodiphenyltrichloroethane and deltamethrin in humans and environmental samples in malarious areas of Mexico. Environmental Research Section A, 88(3), 174-181. http://doi.org/10.1006/enrs.2002.4333

Younas, A., Hilber, I., Rehman, S.U., Khwaja, M. \& Bucheli, T.D. (2013). Former DDT factory in Pakistan revisited for remediation: severe DDT concentrations in soil and plants from within the area. Environmental Science and Pollution Research, 20(4), 1966-1976. https://doi.org/10.1007/ s11356-012-1317-y 